\title{
Excision of a conjugative plasmid from the staphylococcal chromosome
}

\author{
E. E. UDO and W. B. GRUBB
}

\begin{abstract}
School of Medical Technology, Curtin University of Technology, GPO Box U 1987, Perth 6001, Western Australia
\end{abstract}

\begin{abstract}
Summary. Staphylococcus aureus isolate WBG1003 resistant to benzyl penicillin, cadmium, arsenate and streptomycin harbours two plasmids of 38.8 (pWBG621) and 4.4 (pWBG625) kb. In conjugation experiments two types of streptomycin-resistant transconjugants were obtained; one carried a $4 \cdot 4-\mathrm{kb}$ plasmid and the other, a $34 \cdot 5-\mathrm{kb}$ and a 4.4-kb plasmid. The $34 \cdot 5-\mathrm{kb}$ plasmid (pWBG620) has been found to be conjugative and able to mobilise non-conjugative plasmids. It has no detectable resistance phenotype and has not been detected in WBG1003 nor in the recipient used in the conjugation experiments. Restriction endonuclease analysis and DNADNA hybridisation have revealed that pWBG620 is unrelated to pWBG621 present in strain WBG1003. The data presented indicate that pWBG620 is in the chromosome of strain WBG1003 and that it excises during conjugation.
\end{abstract}

\section{Introduction}

Multi-resistant Staphylococcus aureus strains have continued to be a major cause of serious infections in man, both in hospitals and in the community. ${ }^{1}$ Although resistance can be transferred between strains in the laboratory by transduction, mixed-culture transfer and conjugation, it has been suggested that conjugation is the most likely method of genetic exchange in vivo ${ }^{2}$ and has been demonstrated between staphylococci on the human skin. ${ }^{3}$

Three types of conjugative plasmids have now been described in $S$. aureus: those encoding gentamicin, kanamycin and neomycin resistance and sometimes penicillinase production $;{ }^{4-8}$ those producing diffusible pigment (DiP) and encoding resistance to macrolides, lincosamides and streptogramin B and sometimes to kanamycin, neomycin and streptomycin;9,10 and those without any resistance phenotype. ${ }^{11,12}$ These plasmids have been demonstrated in the host cells and, with the exception of the DiP plasmids, mobilise nonconjugative plasmids. It has also been reported that resistance to gentamicin ${ }^{13}$ and mupirocin ${ }^{14}$ can be transferred conjugatively in the absence of detectable conjugative plasmids.

In this paper we report the conjugative transfer

Received 18 Dec. 1989; revised version accepted 30 March 1990. of streptomycin resistance in the absence of a detectable conjugative plasmid in the donor or in the recipient prior to conjugation. Evidence is presented that the donor contains a conjugative plasmid in its chromosome which excises during conjugation and mobilises a non-conjugative, streptomycin-resistance plasmid.

\section{Materials and methods}

Bacteria and plasmids

Bacterial strains and plasmids used are listed in table I.

\section{Media}

Brain Heart Infusion Broth (BHIB), Brain Heart Infusion Agar (BHIA), Trypticase Soy Broth (TSB) and Mueller Hinton Agar (MHA) were purchased from Gibco Diagnostics (Madison, WI, USA).

\section{Susceptibility testing}

Disk diffusion. This was performed on MHA as described previously. ${ }^{15-17}$

Replica plating. The method of Annear and Grubb ${ }^{18}$ was used to replicate to MHA plates containing cadmium $\left(\mathrm{Cd} ; 10^{-2} \mathrm{M}\right)$, streptomycin $(\mathrm{Sm} ; 30 \mathrm{gm} / \mathrm{L})$ or benzylpenicillin $(\mathrm{Pc} ; 2000 \mathrm{U} / \mathrm{L})$. Penicillinase production was determined with nitrocefin. ${ }^{19}$ 
Table I. S. aureus strains and plasmids

\begin{tabular}{|c|c|c|}
\hline Strain no. & Description & Reference \\
\hline WBG248 & Plasmid free & (15) \\
\hline WBG541 & $\mathrm{Fa}^{\mathrm{r}} \mathrm{Rf}^{\mathrm{T}}$ mutant of WBG248 & (15) \\
\hline WBG742 & $\mathrm{Nb}^{\mathrm{r}}$ mutant of WBG 248 & (9) \\
\hline WBG 1876 & WBG541 lysogenised with phage J & (16) \\
\hline WBG4483 & Plasmid mol. wt markers & (20) \\
\hline WBG4515 & $\mathrm{Nb}^{\mathrm{r}} \mathrm{Sm}^{\mathrm{r}}$ mutant of WBG 248 & (11) \\
\hline WBG1003 & $\begin{array}{l}\text { Clinical isolate; } \mathrm{Pc}^{\mathrm{r}}, \mathrm{Cd}^{\mathrm{r}}, \mathrm{Asa}^{\mathrm{r}} ; \mathrm{Sm}^{\mathrm{r}} \text {; harbours } \\
\text { plasmids pWBG621 and pWBG625 }\end{array}$ & \\
\hline pWBG621 & Codes resistance for $\mathrm{Pc}, \mathrm{Cd}, \mathrm{Asa} ; 38.8 \mathrm{~kb}$ & \\
\hline pWBG625 & Codes resistance to $\mathrm{Sm} ; 4.4 \mathrm{~kb}$ & \\
\hline WBG4839 & WBG 1003 cured of $\mathrm{pWBG} 625$ & \\
\hline WBG4840 & WBG 1003 cured of pWBG621 & \\
\hline WBG4841 & $\begin{array}{l}\mathrm{Sm}^{\mathrm{r}} \text { transconjugant of WBG1003/541; har- } \\
\text { bours pWBG625 }\end{array}$ & \\
\hline WBG4842 & $\begin{array}{l}\mathrm{Sm}^{\mathrm{r}} \text { transconjugant of WBG } 1003 / 541 \text {; har- } \\
\text { bours pWBG625 and pWBG620 }\end{array}$ & \\
\hline pWBG620 & Plasmid (34.5 kb), detected after conjugation & \\
\hline WBG4843 & WBG 4842 cured of $p$ WBG 625 & \\
\hline WBG4843-1 & $\begin{array}{l}\text { Transconjugant WBG } 4840 / 541 \text {; harbours plas- } \\
\text { mid pWBG620-1 }(34.5 \mathrm{~kb})\end{array}$ & \\
\hline WBG4844 & WBG 4843 carrying pWBG $3\left(4.4 \mathrm{~kb}, \mathrm{Tc}^{\mathrm{r}}\right)$ & \\
\hline WBG4845 & WBG 4843 carrying pE194 (3.5 kb, Em $\left.{ }^{r}\right)$ & \\
\hline WBG4881 & WBG541 carrying pWBG3 & (11) \\
\hline WBG4882 & WBG541 carrying pE194 & (11) \\
\hline WBG4858 & WBG541 carrying pWBG637 $(34.5 \mathrm{~kb})$ & (11) \\
\hline
\end{tabular}

Asa, arsenate; $\mathrm{Cd}$, cadmium; Em, erythromycin; $\mathrm{Fa}$, fusidic acid; $\mathrm{Nb}$, novobiocin; Pc, benzylpenicillin; Rf, rifampicin; Sm, streptomycin; Tc, tetracycline.

\section{Bacteriophage typing}

Phage typing was performed by Dr D. Perret at the State Health Laboratory Services of Western Australia, Perth.

\section{Loss of resistance at $43 \cdot 5^{\circ} \mathrm{C}$}

Strains were grown either on BHIA or in BHIB at $43.5^{\circ} \mathrm{C}$ for $24 \mathrm{~h}$, plated on to BHIA plates and incubated at $37^{\circ} \mathrm{C}$ overnight. Single colonies were then screened for loss of resistance to antimicrobial agents by the replica plating method. These results were confirmed by the diskdiffusion method.

\section{Transfer of plasmids}

Transduction was performed as described previously ${ }^{15}$ with phage 85 . Mixed culture transfer (MCT) and conjugation experiments were performed as described previously. ${ }^{16,20}$ Briefly, in MCT, $0.1 \mathrm{ml}$ of overnight cultures of donor and recipient were added to $5.0 \mathrm{ml}$ of TSB containing $0.04 \mathrm{M} \mathrm{CaCl}_{2}$. The mixture was incubated overnight at $37^{\circ} \mathrm{C}$ with gentle shaking and then the cells were pelleted by centrifugation. The supernate was discarded and the deposit was spread on BHIA plates containing appropriate selective agents. Selection for resistance was made on plates of either $\mathrm{Cd}\left(10^{-2} \mathrm{M}\right)$ or
Sm $(10 \mathrm{gm} / \mathrm{L})$. The recipient for MCT was strain WBG 1876 which was lysogenised with phage J. ${ }^{16}$

Conjugation studies were performed by the polyethylene glycol (PEG) method ${ }^{20}$ with strain WBG541, a nonlysogenic recipient. Equal volumes $(2 \mathrm{ml})$ of an overnight culture of each of the donor and recipient were mixed in a tube and pelleted by centrifugation. The supernate was discarded and the deposit was resuspended in $0.5 \mathrm{ml}$ of TSB to which was added $5.0 \mathrm{ml}$ oi PEG $40 \% \mathrm{w} / \mathrm{v}$. The tube was then incubated at $37^{\circ} \mathrm{C}$ overnight with gentle shaking. The cells were pelleted by centrifugation and resuspended in $1.0 \mathrm{ml}$ of TSB. From this, serial 10 -fold dilutions were made and $0.1 \mathrm{ml}$ of each dilution was spread on selective media. In both MCT and conjugation experiments, controls consisting of donor and recipients alone were incorporated for each experiment. Transfer frequencies were given as the number of transconjugants in relation to the number of donor cells at the beginning of the experiment. Transfer was considered to have occurred when growth was obtained on selection plates from donor-recipient mixtures but not from selection plates inoculated with the donor and recipient controls.

\section{Plasmid isolation}

Plasmids were isolated by the cetyltrimethylammonium bromide (CTAB) method. ${ }^{21}$ DNA obtained by this method was usually suitable for restriction endonuclease 
analysis. When further purification was necessary, large amounts of plasmid DNA were isolated by the CTAB method and purified by caesium chloride-ethidium bromide density centrifugation. ${ }^{12}$ Horizontal agarose-gel electrophoresis and restriction-enzyme analysis have been described previously. ${ }^{12}$ Vertical gel electrophoresis was performed in TBE buffer ( $445 \mathrm{mM}$ Tris base, $\mathrm{pH} 8.0$, $445 \mathrm{~mm}$ boric acid, $10 \mathrm{~mm}$ EDTA). ${ }^{22}$

\section{DNA-DNA hybridisation}

This was performed as described previously ${ }^{12}$ except that Genescreen Plus (Dupont, Boston, USA) filter membranes were used instead of nitrocellulose.

\section{Results}

\section{Properties of strain WBG1003}

$S$. aureus strain WBG1003 was found to be resistant to benzyl penicillin (Pc), cadmium (Cd), arsenate (Asa) and streptomycin ( $\mathrm{Sm}$ ) and sensitive to erythromycin (Em), lincomycin, tetracycline (Tc), gentamicin, kanamycin, neomycin, chloramphenicol, rifampicin ( $\mathrm{Rf}$ ), fusidic acid ( $\mathrm{Fa})$, mercury, phenylmercuric acetate and to the nucleicacid binding (NAB) compounds such as propamidine isethionate, cetyltrimethylammonium bromide and ethidium bromide. ${ }^{17}$ It was untypable with phages of the International Phage Typing Set and contained plasmids of 38.8 (pWBG621) and $4 \cdot 4$ (pWBG625) kb (fig. 1).

\section{Location of resistance determinants}

Loss of the resistance determinants after growth at $43.5^{\circ} \mathrm{C}$ indicated that all the determinants were plasmid-borne. Resistance to $\mathrm{Pc}, \mathrm{Cd}$ and Asa were lost conjointly whereas $\mathrm{Sm}$ resistance $\left(\mathrm{Sm}^{\mathrm{r}}\right)$ was lost separately. Loss of $\mathrm{Sm}^{\mathrm{r}}$ corresponded to the loss of the 4.4-kb plasmid (pWBG625) and loss of $\mathrm{Pc}^{\mathrm{r}}$, $\mathrm{Cd}^{\mathrm{r}}, \mathrm{Asa}^{\mathrm{r}}$ to the loss of pWBG621 (38.8 kb, fig. 1).

\section{Transfer of resistance determinants}

Plasmid transfer in MCT experiments occurs when either the donor or recipient is lysogenised with a suitable bacteriophage. ${ }^{23}$ Since WBG 1003 was not lysed by phages of the International Typing Set, MCT was attempted with strain WBG1876 (lysogenised with phage $J, 16$ ) as recipient. Strain WBG1876 has been used successfully as recipient in previous MCT experiments with non-typable isolates of $S$. aureus. ${ }^{16}$ None of the resistance determinants of strain WBG1003 was transferred.

When strain WBG 1003 was tested in conjugation

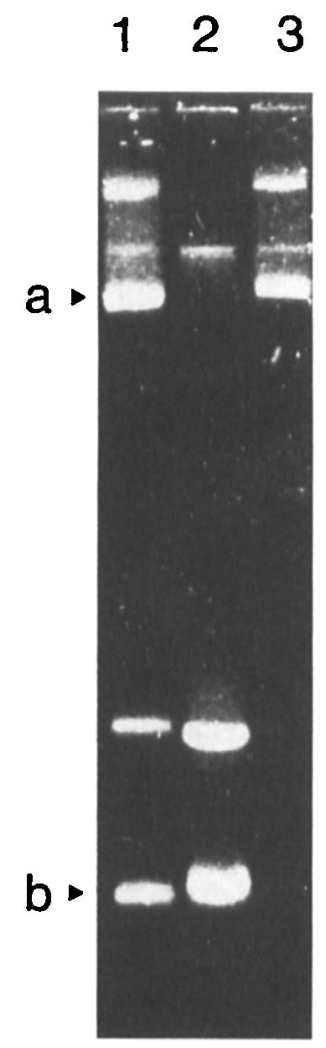

Fig. 1. Plasmids of strain WBG1003. Lane 1: (a) covalentlyclosed circular pWBG621, 38.8 kb; (b) covalently-closed circular pWBG625, $4.4 \mathrm{~kb}$. 2: strain WBG1003 cured of pWBG621 (WBG4840); 3: strain WBG1003 cured of pWBG625 (WBG4839).

experiments with strain WBG541 and selection was made for $\mathrm{Sm}^{\mathrm{r}}$ and $\mathrm{Cd}^{\mathrm{r}}$, transconjugants were obtained on media with $\mathrm{Sm}$ but not Cd selection (table II). None of $227 \mathrm{Sm}^{\mathrm{r}}$ transconjugants screened co-transferred resistance to $\mathrm{Pc}, \mathrm{Cd}$ and Asa. Gel electrophoresis of the $\mathrm{Sm}^{r}$ transconjugants revealed two plasmid profiles. About one-third harboured a single $4 \cdot 4-\mathrm{kb}$ plasmid whereas the remainder contained a $34.5-\mathrm{kb}$ plasmid (pWBG620) and a 4.4-kb plasmid (fig. 2). These results indicate that the $4 \cdot 4-\mathrm{kb}$ plasmid in the transconjugants was the $\mathrm{Sm}^{\mathrm{r}}$ plasmid, pWBG625, from strain WBG1003. A transconjugant containing only pWBG625 was designated strain WBG4841 and one containing both pWBG620 and pWBG625, strain WBG4842 (table I).

\section{Analysis of strain WBG4842}

Strain WBG4842 harboured two plasmids but had only acquired resistance to Sm. Although 
Table II. Transfer of resistance and plasmids by conjugation

\begin{tabular}{llrlr}
\hline $\begin{array}{c}\text { Donor } \\
\text { strain }\end{array}$ & $\begin{array}{c}\text { Recipient } \\
\text { strain }\end{array}$ & $\begin{array}{c}\text { Selective } \\
\text { agents }\end{array}$ & $\begin{array}{l}\text { Resistance and } \\
\text { plasmids (kb) } \\
\text { transferred }\end{array}$ & Frequency \\
\hline WBG1003 & WBG541 & FaRfCd & None & $<1.0 \times 10^{-9}$ \\
WBG1003 & WBG541 & FaRfSm & Sm,4.4 & $1.6 \times 10^{-6}$ \\
WBG1003 & WBG541 & FaRfSm & Sm,4.4;34.5 & $1.6 \times 10^{-6}$ \\
WBG4840 & WBG541 & FaRfSm & Sm,4.4 & $1.2 \times 10^{-6}$ \\
WBG4840 & WBG541 & FaRfSm & Sm,4.4;34.5 & $1.2 \times 10^{-6}$ \\
WBG4841 & WBG742 & NbSm & None & $<1.0 \times 10^{-9}$ \\
WBG4842 & WBG742 & NbSm & Sm,4.4 & $1.4 \times 10^{-6}$ \\
WBG4842 & WBG742 & NbSm & Sm,4.4;34.5 & $1.4 \times 10^{-6}$ \\
WBG4844 & WBG4515 & NbSmTc & Tc,4.4 & $1.0 \times 10^{-6}$ \\
WBG4844 & WBG4515 & NbSmTc & Tc,4.4,34.5 & $1.0 \times 10^{-6}$ \\
WBG4845 & WBG4515 & NbSmEm & Em, 3.5 & $1.2 \times 10^{-7}$ \\
WBG4845 & WBG4515 & NbSmEm & Em, 3.5;34.5 & $1.2 \times 10^{-7}$ \\
WBG4881 & WBG4515 & NbSmTc & None & $<1.0 \times 10^{-9}$ \\
WBG4882 & WBG4515 & NbSmEm & None & $<1.0 \times 10^{-9}$ \\
\hline & & & & \\
\hline
\end{tabular}

$\mathrm{Cd}$, cadmium; Em, erythromycin; Fa, fusidic acid; Rf, rifampicin; $\mathrm{Nb}$, novobiocin; Sm, streptomycin; Tc, tetracycline.

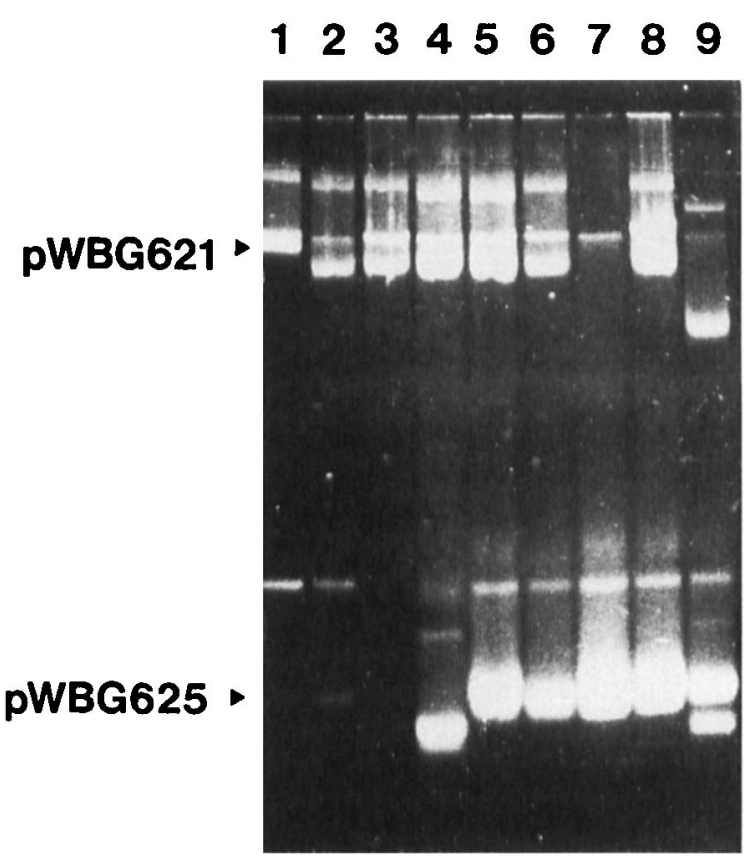

Fig. 2. Strain WBG1003 and its transconjugants. Lane 1, strain WBG1003; 2, strain WBG4842 (pWBG620 and pWBG625); 3, strain WBG4843 (pWBG620); 4, strain WBG4845 or WBG4845/WBG4515 transconjugants containing pWBG620 and pE194; 5, strain WBG4844 (pWBG620 and pWBG3); 6, WBG4844/WBG4515 transconjugant, carrying both pWBG3 and pWBG620; 7, WBG4844/WBG4515 transconjugant carrying only pWBG3;8, same as lane $6 ; 9$, strain WBG4483, plasmid mol.-wt markers (see fig. 5 for details) (pWBG615 is not visible in this gel).
pWBG625 encodes resistance to $\mathrm{Sm}$, it is possible that the $34 \cdot 5-\mathrm{kb}$ plasmid pWBG620 also encodes $\mathrm{Sm}^{\mathrm{r}}$ and that the two plasmids may be responsible for different levels of resistance. However, strains WBG1003, WBG4841 and WBG4842 all had the same MIC to $\operatorname{Sm}(75 \mu \mathrm{g} / \mathrm{ml})$ when tested. It is also possible that $\mathrm{pWBG} 620$ does not encode or express $\mathrm{Sm}^{\mathrm{r}}$ but is conjugative and was only mobilising pWBG625. To confirm this, strains WBG4842 and WBG4841 were tested separately in conjugation experiments with WBG742 and selection was made for $\mathrm{Sm}^{\mathrm{r}} . \mathrm{Sm}^{\mathrm{r}}$ was transferred only from strain WBG4842, confirming that the $34 \cdot 5-\mathrm{kb}$ plasmid was conjugative and was mobilising pWBG625. When the WBG4842/WBG742 transconjugants were analysed for plasmid content they were found to be of two types, similar to those obtained when strain WBG1003 was the donor. One type carried a single $4 \cdot 4-\mathrm{kb}$ plasmid and the other both the $34 \cdot 5-$ $\mathrm{kb}$ and $4 \cdot 4-\mathrm{kb}$ plasmids.

To study pWBG620 further, attempts were made to isolate it on its own. Strain WBG4842 was grown at $43.5^{\circ} \mathrm{C}$ for $48 \mathrm{~h}$ and single colonies were screened for loss of $\mathrm{Sm}^{\mathrm{r}}$. When $\mathrm{Sm}^{\mathrm{s}}$ colonies were analysed for plasmid content, they were found to have lost both plasmids. Strain WBG4842 was then grown at $37^{\circ} \mathrm{C}$ for $48 \mathrm{~h}$ and single colonies were screened for loss of $\mathrm{Sm}^{\mathrm{r}}$. Two $\mathrm{Sm}^{\mathrm{s}}$ colonies were obtained out of 168 examined. Plasmid analysis revealed that the $\mathrm{Sm}^{\mathrm{s}}$ colonies had lost pWBG625 but retained pWBG620. One of these colonies was designated strain WBG4843 (table I; fig. 2). 


\section{Characterisation of $p W B G 620$}

Strain WBG4843, containing only pWBG620, was tested for resistance to antibiotics, heavy metals ${ }^{15}$ and NAB compounds. ${ }^{17}$ It was found to be resistant only to $\mathrm{Rf}$ and $\mathrm{Fa}$, the two chromosomal resistance markers of strain WBG541.

The ability of pWBG620 to mobilise plasmids other than pWBG625 was studied by transducing pWBG3 $\left(\mathrm{Tc}^{\mathrm{r}}\right)$ and pE194 $\left(\mathrm{Em}^{\mathrm{r}}\right)$ to strain WBG4843 in separate experiments to produce strains WBG4844 and WBG4845 respectively. Strains WBG4844 and WBG4845 were conjugated with strain WBG4515 in separate experiments and selection was made for the phenotypes of the nonconjugative plasmids and the chromosomal resistances of strain WBG4515. In both cases the nonconjugative plasmids were transferred into strain WBG4515 (table II; fig. 2). When transconjugants were analysed for plasmid content, they were found to be of two types; one type carried only the nonconjugative plasmid and the other type carried both the conjugative and non-conjugative plasmids. Conjugation experiments were also performed with strain WBG4515 and donors carrying only the nonconjugative plasmids pWBG3 (WBG4881) and pE194 (WBG4882). No transfer was observed in either case, which confirms that both pWBG3 and $\mathrm{pE} 194$ would not transfer by conjugation in the absence of pWBG620.

\section{Origin of pWBG620}

As plasmid pWBG620 cannot be detected in the parent strain WBG1003, and is only observed in transconjugants (fig. 2), this raises the question of its origin. Since strain WBG1003 harbours a 38.8$\mathrm{kb}$ plasmid ( $\mathrm{pWBG621)}$ encoding resistance to $\mathrm{Pc}$, Cd and Asa, pWBG620 is possibly related to it and results from the deletion of the resistance determinants during conjugation. If this is the case, then both plasmids, pWBG620 and pWBG621, would have DNA sequences in common. However the plasmids did not have common fragments when digested with restriction enzymes $B g l \mathrm{II}, \mathrm{ClaI}, \mathrm{HpaII}$ (fig. 3) and EcoRI (fig. 4A) and no homology was detected when ${ }^{32}$ P-labelled pWBG620 was hybridised with pWBG621 (fig. 4).

Any role for pWBG621 was further discounted by conjugating strain WBG4840, a derivative of strain WBG1003 cured of pWBG621, with strain WBG541. $\mathrm{Sm}^{\mathrm{r}}$ was transferred to strain WBG541 (table II; fig. 5) and the transconjugants were similar to those obtained when strain WBG1003 was used as donor. One of the $34 \cdot 5-\mathrm{kb}$ plasmids,

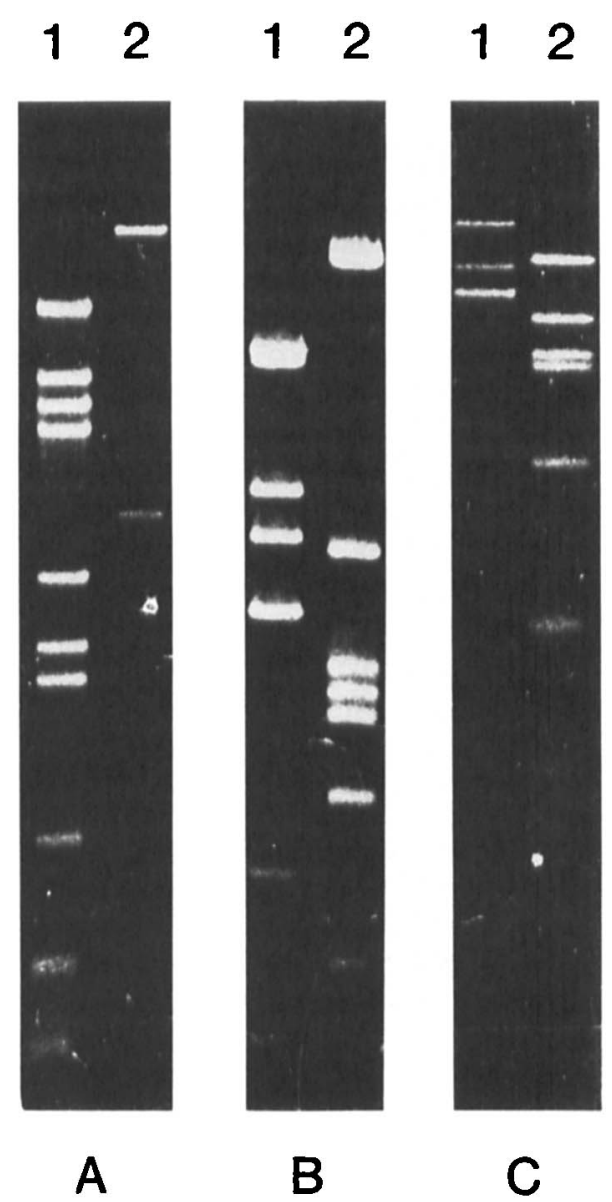

Fig. 3. Restriction endonuclease analysis of plasmids pWBG621 and pWBG620 with (A) BglII, (B) ClaI and (C) HpaII. Lanes 1, pWBG621; 2, pWBG620.

pWBG620-1, from the WBG4840/WBG541 transconjugants was isolated and cut with EcoRI restriction enzyme. It gave the same sized fragments as pWBG620 (not shown).

Since pWBG620 appears not related to pWBG621, there would appear to be three possible explanations for its origin. Firstly, it could have been introduced by a contaminating strain such as WBG1024 carrying plasmid pWBG637. ${ }^{11} \mathrm{Sec}-$ ondly, it could have been derived from a larger plasmid not detected in strain WBG1003, or thirdly it could have excised from the chromosome of the donor strain WBG1003.

To test if pWBG620 was due to a contaminating strain, single colonies of WBG1003 were used in conjugation experiments using WBG541 as recipient. Two of seven single colony isolates transferred $\mathrm{Sm}^{\mathrm{r}}$. Analysis of the seven single-colony clones and 


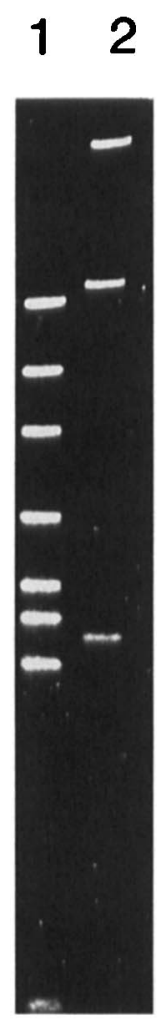

A

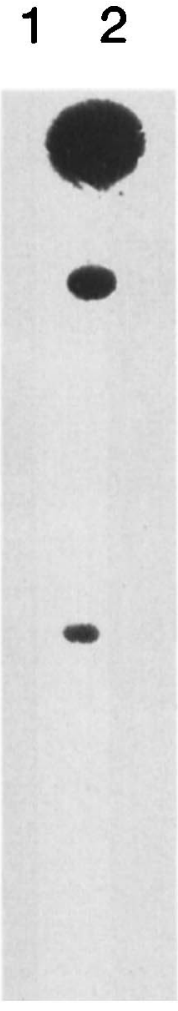

B

Fig. 4. Southern blot analysis of plasmids pWBG621 and pWBG620. (A) EcoRI analysis of plasmids pWBG621 (Lane 1) and pWBG620 (2). (B) Autoradiograph of gel in panel A after Southern transfer and hybridisation with ${ }^{32} \mathrm{P}$-labelled pWBG620.

strain WBG1003 did not reveal any differences in plasmid content (not shown) which eliminates the possibility that some of the cells were carrying a plasmid of the pWBG637 type.

Plasmid pWBG620 was possibly derived from a large plasmid in strain WBG1003 which was not detected on horizontal gel electrophoresis. However, when the preparations were run on vertical gel electrophoresis, no additional plasmids were detected in strain WBG1003. These results are consistent with the hypothesis that pWBG620 is located on the chromosome of strain WBG1003 and that it excises during conjugation.

\section{Comparison of plasmids pWBG620 and pWBG637}

Plasmid pWBG620 appeared to be similar to pWBG637 which has been reported previously to be conjugative and without any resistance phenotype. ${ }^{11}$ Both plasmids appeared to have the same

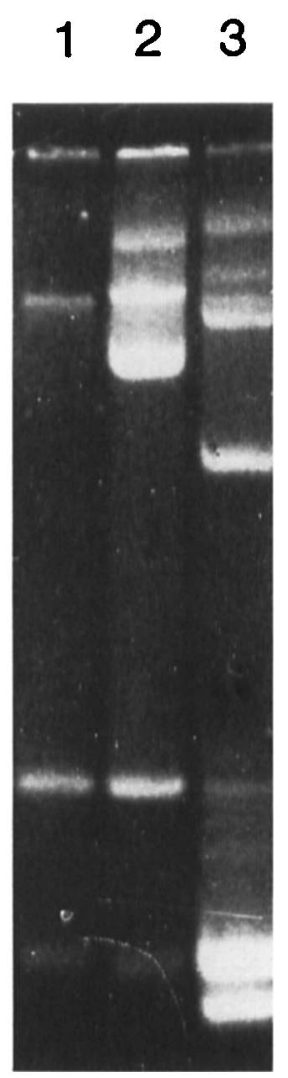

Fig. 5. WBG4840/WBG541 transconjugants. Lane 1, strain WBG4840 or representative of WBG4840/WBG541 transconjugants carrying only pWBG625;2, representative of WBG4840/ WBG541 transconjugants carrying both pWBG620-1 and pWBG625; 3, strain WBG4483, plasmid mol.-wt markers from top, open circular, OC, pWBG615, 40.3 kb; OC pWBG115, $22.5 \mathrm{~kb}$; chromosomal DNA; covalently-closed, CCC, pWBG615; CCC pWBG115; OC pWBG3, 4.4 kb; OC pE194, $3.5 \mathrm{~kb}$; CCC pWBG3; CCC pE194.

molecular weight and generated the same fragments when digested with $E c o$ RI, HindIII, ClaI and HpaII (not shown). Furthermore, pWBG620 hybridised with a ${ }^{32} \mathrm{P}$-labelled pWBG637 probe in a Southern hybridisation experiment ${ }^{12}$ which indicates that the two plasmids are identical or very similar.

\section{Discussion}

Only two plasmids have been detected in strain WBG1003-one of 4.4-kb encoding $\mathrm{Sm}^{\mathrm{r}}$ (pWBG625) and one of $38 \cdot 8-\mathrm{kb}$ encoding $\mathrm{Pc}^{\mathrm{r}}, \mathrm{Cd}^{\mathrm{r}}$, $\mathrm{Asa}^{\mathrm{r}}$ (pWBG621). Since strain WBG1003 is untypable with phages of the International Typing Set, it was not possible to transduce the plasmids. Attempts to transfer the plasmids in MCT were also 
unsuccessful. However, pWBG625 was transferred during conjugation. Its transfer was due to a $34 \cdot 5-$ $\mathrm{kb}$ plasmid, pWBG620, which was not detectable in strain WBG1003 and had no homology with pWBG621, the $38 \cdot 8-\mathrm{kb}$ plasmid found in strain WBG1003. When conjugation was performed with strain WBG4840, the parent strain WBG 1003 lacking pWBG621, pWBG625 was mobilised by a plasmid indistinguishable from pWBG620. There is no evidence that a third plasmid exists extrachromosomally in strain WBG1003. Plasmid pWBG620 was not detected on horizontal or vertical gels. Vertical gel electrophoresis has been used to separate large mol.-wt plasmids (>100 kb) in gram-negative bacilli. ${ }^{24,25}$ To our knowledge, no plasmids of this size have been reported in $S$. aureus. The implication, from these results, is that pWBG620 is integrated in the chromosome of strain WBG1003, excises during conjugation and mobilises pWBG625.

Plasmid pWBG620 has no detectable resistance phenotype and appears to be indistinguishable from pWBG637, a conjugative plasmid described in another isolate. ${ }^{11}$ This similarity was confirmed by restriction enzyme analysis and DNA-DNA hybridisation. ${ }^{12}$ However, there is no evidence that pWBG 637 is able to integrate into the chromosome of its host strain WBG1024. Also, neither pWBG637 nor pWBG620 appears to be able to integrate into the chromosome of transconjugants. In every case examined, plasmids could be mobilised only from transconjugants if either pWBG637 or pWBG620 was detected. Consequently, it would appear that strain WBG1003 must have some property, such as a specific integration site, which enables pWBG620 to integrate into the chromosome. Once pWBG620 has excised or mobilises another plasmid, it appears to be unable to integrate into the chromosome of the transconjugants. This may be how pWBG637 arose initially.

The nature of pWBG620 within the chromosome of strain WBG1003 has not yet been determined. Either it exists as an integrated plasmid and excises precisely during conjugation, or it is formed as a result of excisive recombination between insertion sequences (IS) in the chromosome. Different IS elements have been shown to be involved in the excision of Type-II F-prime plasmids in Esherichia

\section{REFERENCES}

1. Shanson DC. Antibiotic-resistant Staphylococcus aureus. $J$ Hosp Infect 1981 ; 2: 11-36.

2. Lacey RW. Antibiotic resistance in Staphylococcus aureus and streptococci. Br Med Bull 1984; 40: 77-83.

3. Townsend DE, den Hollander L, Bolton S, Grubb WB. coli $^{26,27}$ and cryptic plasmids in Pseudomonas syringae pv phaseolicola. ${ }^{28}$ DNA-DNA hybridisation analysis of the chromosome of strain WBG 1003 with various fragments of $\mathrm{pWBG} 620$ as probes will provide physical evidence of the integration of pWBG620. Inability of five of the seven single colonies examined to transfer $\mathrm{Sm}^{\mathrm{r}}$ could be due to the absence of pWBG620 in their chromosomes or the integrated plasmids are excision defective. The probes of pWBG620 could also be used to clarify the situation. In the meantime the results presented provide genetic evidence that pWBG620 does excise from the chromosome of strain WBG1003 during conjugation.

Although cryptic conjugative plasmids capable of excising from the chromosome have been reported in Streptomyces spp., ${ }^{29-32}$ Haemophilus influenzae, ${ }^{33}$ Lactobacillus acidophilus ${ }^{34}$ and the plant pathogen $P$. syringae, ${ }^{28,35}$ this is the first time a conjugative plasmid has been reported to excise from the chromosome in staphylococci.

These results may explain reports of other resistance determinants being transferred during conjugation in the apparent absence of a conjugative plasmid. Recent examples are the transfer of gentamicin $^{13}$ and mupirocin ${ }^{14}$ resistances in the absence of detectable conjugative plasmids either in the donor or in the transconjugants. This does not however exclude the possibility that conjugative transposons may also be involved.

Until recently the only conjugative plasmids reported in the staphylococci are those conferring resistance to gentamicin and kanamycin ${ }^{4-8}$ and the DiP plasmids. ${ }^{9,10}$ The discovery of a new class of conjugative plasmids which do not have any resistance phenotype and which are able to mobilise non-conjugative plasmids, ${ }^{11,12}$ further extends the scope of resistance transfer in the staphylococci. The finding that this class of plasmid probably can excise from the chromosome, at least of some staphylococci, raises the possibility that they may be able to transfer chromosomal determinants.

We thank Dr D. Perret for phage typing. This work was supported by grants to WBG from the National Health and Medical Research Council of Australia. EEU was a recipient of a Curtin University of Technology Postgraduate Research Scholarship.

Clinical isolates of staphylococci conjugate on contact with dry absorbent surfaces. Med $J$ Aust 1986; 144: 166.

4. Archer GL, Johnston JL. Self-transmissible plasmids in staphylococci that encode resistance to aminoglycosides. Antimicrob Agents Chemother 1983; 24: 70-77.

5. Forbes BA, Schaberg DR. Transfer of resistance plasmids 
from Staphylococcus epidermidis to Staphylococcus aureus: evidence for conjugative exchange of resistance. $J$ Bacteriol 1983; 153: 627-634.

6. McDonnel RW, Sweeney HM, Cohen S. Conjugational transfer of gentamicin resistance plasmids intra- and interspecifically in Staphylococcus aureus and Staphylococcus epidermidis. Antimicrob Agents Chemother 1983; 23: $151-160$.

7. Grubb WB, Townsend DE, Ashdown N, Taheri S. A genetic comparison of methicillin-resistant Staphylococcus aureus isolated from different countries. In: Ishigami $\mathbf{J}$ (ed) Recent advances in chemotherapy. Tokyo, University of Tokyo Press. 1985: 401-402.

8. Evans J, Dyke KGH. Characterization of the conjugation system associated with the Staphylococcus aureus plasmid pJE1. J Gen Microbiol 1988; 134: 1-8.

9. Townsend DE, Ashdown N, Annear DI, Grubb WB. A conjugative plasmid encoding production of a diffusible pigment and resistance to aminoglycosides and macrolides in Staphylococcus aureus. Aust J Exp Biol Med Sci $1985 ; 63$ : 573-586.

10. Townsend DE, Bolton S, Ashdown N, Annear DI, Grubb WB. Conjugative staphylococcal plasmids carrying hitch-hiking transposons similar to Tn554: intra- and interspecies dissemination of erythromycin resistance. Aust J Exp Biol Med Sci 1986; 64: 367-379.

11. Udo E, Townsend DE, Grubb WB. A conjugative staphylococcal plasmid with no resistance phenotype. FEMS Microbiol Lett 1987; 40: 279-283.

12. Udo E, Grubb WB. A new class of conjugative plasmids in Staphylococcus aureus. J Med Microbiol 1990; 31 : 207212.

13. El Solh N, Allignet J, Bismuth R, Buret B, Fouace JM. Conjugative transfer of staphylococcal antibiotic resistance markers in the absence of detectable plasmid DNA. Antimicrob Agents Chemother 1986; 30: 161-169.

14. Rahman M, Noble WC, Cookson B. Transmissible mupirocin resistance in Staphylococcus aureus. Epidemiol Infect 1989; 102: 261-270.

15. Townsend DE, Grubb WB, Ashdown N. Gentamicin resistance in methicillin-resistant Staphylococcus aureus. Pathology 1983; 15 : 169-174.

16. Townsend DE, Ashdown N, Greed LC, Grubb WB. Transposition of gentamicin resistance to staphylococcal plasmids encoding resistance to cationic agents. $J$ Antimicrob Chemother 1984; 14: 115-124.

17. Emslie KR, Townsend DE, Bolton S, Grubb WB. Two distinct resistance determinants to nucleic acid-binding compounds in Staphylococcus aureus? FEMS Microbiol Lett 1985; 27: 61-64.

18. Annear DI, Grubb WB. Linked and unstable resistance to kanamycin and penicillin and diffusible pigment production, in an isolate of Staphylococcus aureus. $J$ Med Microbiol 1972; 5: 109-111.

19. O'Callaghan CH, Morris A, Kirby SM, Shingler AH. Novel method for detection of beta-lactamase by using a chromogenic cephalosporin substrate. Antimicrob Agents Chemother 1972; 1: 283-288.

20. Townsend DE, Bolton S, Ashdown N, Taheri S, Grubb
WB. Comparison of phage-mediated and conjugative transfer of staphylococcal plasmids in vitro and in vivo. J Med Microbiol 1986; 22 : 107-114.

21. Townsend DE, Ashdown N, Bolton S, Grubb WB. The use of cetyltrimethylammonium bromide for the rapid isolation from Staphylococcus aureus of relaxable and non-relaxable plasmid DNA for in vitro manipulation. Lett Appl Microbiol 1985; 1: 87-94.

22. Maniatis T, Fritsch EF, Sambrook J. Molecular cloning: a laboratory manual. Cold Spring Harbor N.Y., Cold Spring Harbor Laboratory. 1982.

23. Lacey RW. Evidence for two mechanisms of plasmid transfer in mixed cultures of Staphylococcus aureus. $J$ Gen Microbiol 1980; 119 : 423-435.

24. Meyers JA, Sanchez D, Elwell LP, Falkow S. Simple agarose gel electrophoretic method for the identification and characterisation of plasmid deoxyribonucleic acid. $J$ Bacteriol 1976; 127: 1529-1537.

25. Wachsmuth K, DeBoy J, Birkness K, Sack D, Wells J. Genetic transfer of antimicrobial resistance and enterotoxigenicity among Escherichia coli strains. Antimicrob Agents Chemother 1983; 23: 278-283.

26. Timmons MS, Bogardus AM, Deonier RC. Mapping of chromosomal IS5 elements that mediate type II Fprime plasmid excision in Escherichia coli K-12. $J$ Bacteriol 1983 ; 153; 395-407.

27. Deonier RC, Mirels L. Excision of F plasmid sequences by recombination at directly repeated insertion sequence 2 elements: involvement of recA. Proc Natl Acad Sci USA 1977; 74: 3965-3969.

28. Szabo LJ, Mills D. Integration and excision of pMC7105 in Pseudomonas syringae pv phaseolicola: involvement of repetitive sequences. $J$ Bacteriol 1984; 157: 821-827.

29. Bibb MJ, Ward JM, Kieser T, Cohen SN, Hopwood DA. Excision of chromosomal DNA sequences from Streptomyces coelicolor forms a novel family of plasmids detectable in Streptomyces lividans. Mol Gen Genet $1981 ; 184$ : 230-240.

30. Cohen A, Bar-Nir D, Goedeke ME, Parag Y. The integrated and free states of Streptomyces griseus plasmid pSG1. Plasmid $1985 ; 13$ : 41-50.

31. Hopwood DA, Hintermann G, Kieser T, Wright HM. Integrated DNA sequences in three streptomyces form related autonomous plasmids after transfer to Streptomyces lividans. Plasmid 1984; 11 : 1-16.

32. Simonet J-M, Boccard F, Pernodet J-L, Gagnat J, Guerineau M. Excision and integration of a self-transmissible replicon of Streptomyces ambofaciens. Gene 1987; 59: 137-144.

33. Stuy JH. Chromosomally integrated conjugative plasmids are common in antibiotic-resistant Haemophilus influenzae. J Bacteriol 1980; 142: 925-930.

34. Muriana PM, Klaenhammer TR. Conjugal transfer of plasmid-encoded determinants for bacteriocin production and immunity in Lactobacillus acidophilus 88. Appl Environ Microbiol 1987; 53: 553-560.

35. Szabo LJ, Mills D. Characterisation of eight excision plasmids of Pseudomonas syringae pv phaseolicola. Mol Gen Genet 1984; 195: 90-95. 